\title{
PHYSICAL EDUCATION AND SPORT
}

\section{ASSESSMENT OF SOMATIC HEALTH, PHYSICAL AND MENTAL WORKABILITY OF 10-11 YEARS OLD STUDENTS}

\section{Oleksandr Piven ${ }^{1}$ Mykola Gorbenko}

DOI: https://doi.org/10.30525/978-9934-588-39-6-21

Focus of Problem. In many cases, secondary school has an adverse impact on students' health, and innovative educational establishments often accumulate the drawbacks of a traditional school, even deepening that impact. Intensification of an educational and pedagogical process preconditions the increased requirements to students' functional overall sense of wellbeing. As a result, different changes may occur that are characterized by decrease of a human body functional capabilities; tension in regulating systems, that may cause the impairment of a mental workability and restriction of adaptive and adaptable capabilities [1; 3; 8]. Excessive educational workload, insufficient motion activity, disruptions in educational process and daily routine unfavorably influence children's organisms that are not entirely formed yet [4; 8]. With the realization of technology of creative learning, the majority of students suffer from fatigue accompanied by the workability decrease and morbidity decrease [2; 5]. Functional overall sense of wellbeing of the 10-11 years old students has been analyzed; and the analyses are based on the heart rate variability. The results of the study demonstrate that the most distinct tension of adaptation are inherent to the group of students with the high rate of academic performance together with intensive methods of education [4]. Therefore, the role of school in formation of different types of pathology is evident.

The condition of students' somatic health depends upon many factors, and in their turn, they may have a positive impact on students, as well as be a substantial threat with negative consequences. It is determined that $17,5 \%$ students complain about organism functional disorders [3]; and that the continuous sedentary poses become the risk factor for the manifestations of cardiovascular diseases [6]. It is also ascertained that among the hygienic factors in educational establishments of a new format, the secondary school pressure plays a crucial role [1], and a long-term usage of modern information

\footnotetext{
${ }^{1}$ Pereyaslav-Khmelnytsky Hryhorii Skovoroda State Pedagogical University, Ukraine

${ }^{2}$ Pereyaslav-Khmelnytsky Hryhorii Skovoroda State Pedagogical University, Ukraine
} 
and communication technologies invoke strong emotions and cause a cognitive fatigue [7].

It is proved that the difference in methodology of physical education depends on the type of school [5], and in case the amount of hours of mental load is increased due to decreasing of hours of physical training, a certain threat for health occurs [4].

Aim of the Research. To identify the main factors that influence the state of somatic health and workability of 10-11 years old schoolboys at the begging and at the end of the school year.

Results of the Research and Discussion. 120 boys of 10-11 years old took place in the research. The boys locate in Pereyaslav-Khmelnytskyi Town, Kyiv Region, and they belong to the main medical group according to their health condition. The boys were sectioned equally into groups of 60 people in every age.

The research was made on the basis of received indicators of testing of previous researches that were conducted according to the methodology for identification of children's health condition, suggested by T. Krutsevich [2].

Based on the analyses of data that characterize anthropometric indicators, physical and functional condition of the 5-6 grade students, the most substantial indicators were identified that determine factor structure of somatic health of 10-11 years old boys at the beginning and at the end of a school year. At the beginning of a school year, among the 10 years old boys, $5,7 \%$ (4 people) were registered with high-level indicators of somatic health, and $25,7 \%$ (18 people) were registered with the low-level indicators. At the end of the school year the amount of students with low-level indicators of somatic health increased and constituted $47,2 \%$ (33 people). This proves that students that had high-level indicators of somatic health at the beginning of the year, could not retain them till the end of the year.

Therefore, the increase of amount of students with low-level indicators of somatic health from 18 till 33 students (increase for 83,6\%) at the end of a school year is explained by decrease of the level of impact on the general dispersion of mental efficiency indicators, preparation and physical workability.

As a result, the significance of indicators of mental efficiency and physical workability for the formation of majority of the factor load from the general dispersion decreased by $24,2 \%$ at the end of the school year. At the same time, the increase of indicator of unorganized, uncalculated factors also testify about increased intellectual fatigue and decrease of mental efficiency; and the amount of such factors increase by $4,25 \%$ at the end of the school year. The mentioned changes can be explained by the increase of an intellectual load that include: school subjects Olympiads, exams preparation, increased requirements of teachers to their subjects; and, as a result, the mental fatigue occur. 
In the group of 11 years old students there were 9 boys (12,8\%) with highlevel indicators of somatic health and 10 boys (14,3\%) with low-level indicators at the beginning of a school year. At the end of the school year the amount of students with low-level indicators of somatic health increased fourfold and constituted 54,2\% (38 people); and there were no student with the low-level indicators. On the basis of analysis of four groups of main factors that affect the somatic health of 6-grade students, it is determined that from the beginning of a school year the general dispersion constituted $70,61 \%$ from the full dispersion; and at the end of the year $-65,73 \%$. Thereby, the amount of uncalculated, unorganized, factors is equal to $29,39 \%$ and $34,26 \%$.

Thus, according to percentage calculation, increase of amount of unorganized factors constitutes 16,6\%.

It is undoubtedly that the research students requires intensification of control over health and wellbeing, conditions, and organization of educational activity, as well as activities, targeted at their improvement and optimization [2; 4].

Conclusions. More distinct level of decrease of somatic health indicators at the end of a school year goes along with a substantial decrease of impact on certain factors and general dispersion of indicators of frequency of heart contraction, blood pressure, mental and physical workability, intellectual sharpness, Ruffier and Robinson indexes.

A considerable increase of indicators of unorganized factors at the end of a school year, especially at 11 years old students, is explained by intensification of impact of non-identified factors, as a result of high intellectual load at this stage of educational process.

Self-assessment of health, level of physical training, and estimation of favorability of conditions of studying at school, with the aim of preserving health, as well as leading a healthy lifestyle by students of 10-11 years old depends on the type of an educational establishment and specifics of organization of an educational process in it.

Perspective of further research. The further research will be targeted at seeking of optimal physical load that are accessible under conditions of modern intellectual stress.

The research undertaken does not deplete the problem of examining of physical workability and motivation of students for physical selfimprovement, and also touches a series of questions concerning forming of attitude of students of different age group towards physical training exercises. 


\section{References:}

1. Hrebniak M.P. (2002) «Social and Medical Risk Factors for Children Health. Protection of Health of Ukraine.», № 3 4(6-7), p. 12-14.

2. Krutsevich T. Iu. (1999) «Methods of Examination of Individual Health of Children and Teenagers in the Process of Physical Education», Textbook for Students of Physical Training and Sport Educational Establishments. Kyiv, 232 p.

3. Dotsoev L. Ia., Usynin A. M., Vagner N. I., Yutatchikov A. T. (2003) «Functional State of 11-12 Years Old Students under Intensive Educational Load According to the Analyses of Heart Rhythm Variability», Human Physiology, Vol. 29, № 4, p. 62-65.

4. Khohlova L. A., Bondar T. S., Sutula A. V. (2010) «Some Factors Influencing Students’ Health», Physical Training of students, № 4, p. 70-73.

5. François T., Roy J Shephard (2008) «Physical Education, School Physical Activity, School Sports and Academic Performance», International Journal of Behavioral Nutrition and Physical Activity, № 5(3), p. 74-83.

6. Greenfield J.R.F., Almond M, Clarke G.P. Edwards K.L. (2015) «Factors Affecting School Physical Education Provision in England: a Cross-Sectional Analysis», Public Health, № 7(2), p. 101-109.

7. Hamilton MT, Healy GN, Dunstan DW, Zderic TW, Owen N (2008) «Too Little Exercise and too Much Sitting: Inaction, Physiology and the Need for New Recommendations for a Sedentary Lifestyle», Tech Cardiovascular Risk Rep, № 2(4), p. 292-298.

8. Marjut Wallenius, Ari Hirvonen, Harri Lindholm, Arja Rimpelä, Clas-Hakan Nygård, Lea Saarni, Raijaeena Punamäki (2010) «Salivary Cortisol in Relation to the Use of Information and Communication Technology (ICT) in School-Aged Children», Psychology, № 1, p. 88-95. 